\title{
Mediastinal chyloma after esophageal cancer resection: An unusual complication causing left cardiac failure
}

\author{
Manuel Pera, MD, PhD, José Belda, MD, Oscar Vidal, MD, Matilde Rubio, MD, and Luis Grande, MD, PhD, Barcelona, Spain
}

$\mathrm{P}$ ostoperative mediastinal chyloma is an extremely rare complication after thoracic surgery. ${ }^{1,2}$ We report a case of a large mediastinal chyloma that developed after a seemingly successful conservative treatment for postesophagectomy chylothorax.

\section{Clinical Summary}

A 51-year-old man was referred to our upper gastrointestinal surgical unit because of a 4-month history of dysphagia of solids. Endoscopy revealed an ulcerated lesion located at $25 \mathrm{~cm}$ from the incisors. Biopsy specimens confirmed the diagnosis of squamous cell carcinoma of the esophagus. Clinical staging resulted in the diagnosis of a locally advanced supracarinal tumor (T3-4 N1 M0). The patient received neoadjuvant multimodal therapy consisting of concurrent cisplatin and fluorouracil administration and radiation therapy. Dysphagia improved, but response evaluation demonstrated only partial response. A 3-stage esophagectomy with 2-field lymphadenectomy was performed with an esophagogastrostomy at the cervical level. Histopathologic study revealed complete pathologic response.

Oral ingestion was started on postoperative day 7, and the day after approximately $650 \mathrm{~mL}$ of white, turbid fluid was drained through the chest tube. A chylothorax was diagnosed, and we started conservative treatment with total parenteral nutrition. After 1 week the pleural fluid decreased, and we again initiated oral ingestion, this time without observing the reappearance of the chylothorax. A control chest radiograph did not reveal pleural effusion. Twenty-two days after the esophagectomy, the patient was discharged from the hospital.

Five days later, the patient came to the outpatient clinic with retrosternal oppressive pain, orthopnea, and dysphagia. Chest radiography showed a significant left pleural effusion, which was immediately drained, yielding $1200 \mathrm{~mL}$ of clear fluid. Pleural effusion did not accumulate thereafter, but the patient continued to have retrosternal pain and severe orthopnea. A barium swallow demonstrated severe stomach angulation secondary to an external

From the Service of Gastrointestinal Surgery, Esophagogastric Cancer Unit, Institut de Malalties Digestives, and Institut d'Investigacions Biomèdiques August Pi I Sunyer Hospital Clinic, University of Barcelona Medical School, Barcelona, Spain

Received for publication Dec 18, 2001; accepted for publication Jan 11, 2002

Address for reprints: Manuel Pera, MD, PhD, Service of Gastrointestinal Surgery, Hospital Clinic, University of Barcelona Medical School, Villarroel 170, Barcelona 08036, Spain (E-mail: mpera@medicina.ub.es).

J Thorac Cardiovasc Surg 2002;124:198-9

Copyright (C) 2002 by The American Association for Thoracic Surgery

$0022-5223 / 2002 \$ 35.00+0 \quad \mathbf{1 2 / 5 4 / 1 2 2 9 6 8}$

doi: $10.1067 / \mathrm{mtc} .2002 .122968$ compression (Figure 1). Echocardiography was performed and showed severe compression of the left atrium by a cystic mass. Chest computed tomographic scan showed a low-density mass surrounded by a thick, contrast-enhanced capsule in the upper mediastinum. The mass compressed the left atrium, the trachea, and the interposed stomach (Figure 2). Because the clinical situation of the patient was deteriorating, surgical intervention was indicated. A right thoracotomy revealed anterior displacement of the interposed stomach, and dissection of the plane between the stomach and the vertebral spine allowed us to enter a big cavity containing a coagulated, milky collection. This collection extended from the upper mediastinum to the hiatal area. Because it was impossible to localize the thoracic duct, we used fibrin glue all along the posterior mediastinum and performed an abrasive pleurodesis. The postoperative course was uneventful, and the patient was discharged free of symptoms 10 days after the operation.

\section{Discussion}

The accumulation of chyle within the mediastinal space has been reported by several investigators. This rare complication has been predominantly described in patients sustaining a closed chest trauma. ${ }^{3,4}$ Postoperative mediastinal chyloma, in contrast, has been reported in only 2 previous cases. ${ }^{1,2}$ Riquet and colleagues ${ }^{1}$ observed a chylomediastinum after mediastinoscopy. Suzuki and associates $^{2}$ reported a mediastinal chyloma that developed in a 69-year-old woman who had undergone right upper lobectomy and lymph node dissection. The initial postoperative chylothorax was managed with chemical pleurodesis, but persistence of the chylous leakage within the right upper mediastinum led to the development of a chyloma. This anterior mediastinal mass compressed the superior vena cava and trachea.

To our knowledge, mediastinal chyloma after esophageal surgery has not been previously reported. In our case, the initial postoperative chylothorax was managed conservatively with total parenteral nutrition. This therapeutic option seemed to be successful, with a complete reduction of the pleural fluid through the chest tubes. However, chylous leakage persisted and accumulated within the space delimited by the interposed stomach, trachea, left atrium, and great vessels. Dyspnea, orthopnea, and slight dysphagia were the symptoms caused by the increasing size of this mediastinal mass. The appearance of this clinical picture after a seemingly successful treatment for postoperative chylothorax should prompt the surgeon to rule out the accumulation of chyle within the mediastinum. Chest computed tomographic scan was useful in the diagnosis. In addition, the displacement of the stomach anteriorly, as observed in the barium swallow, also suggested the presence of external compression by a mass. Removal of the chylous collection and abrasive pleurodesis, in association with fibrin glue application in those cases where the thoracic duct cannot be identified, may successfully manage this uncommon but life-threatening postesophagectomy complication. 

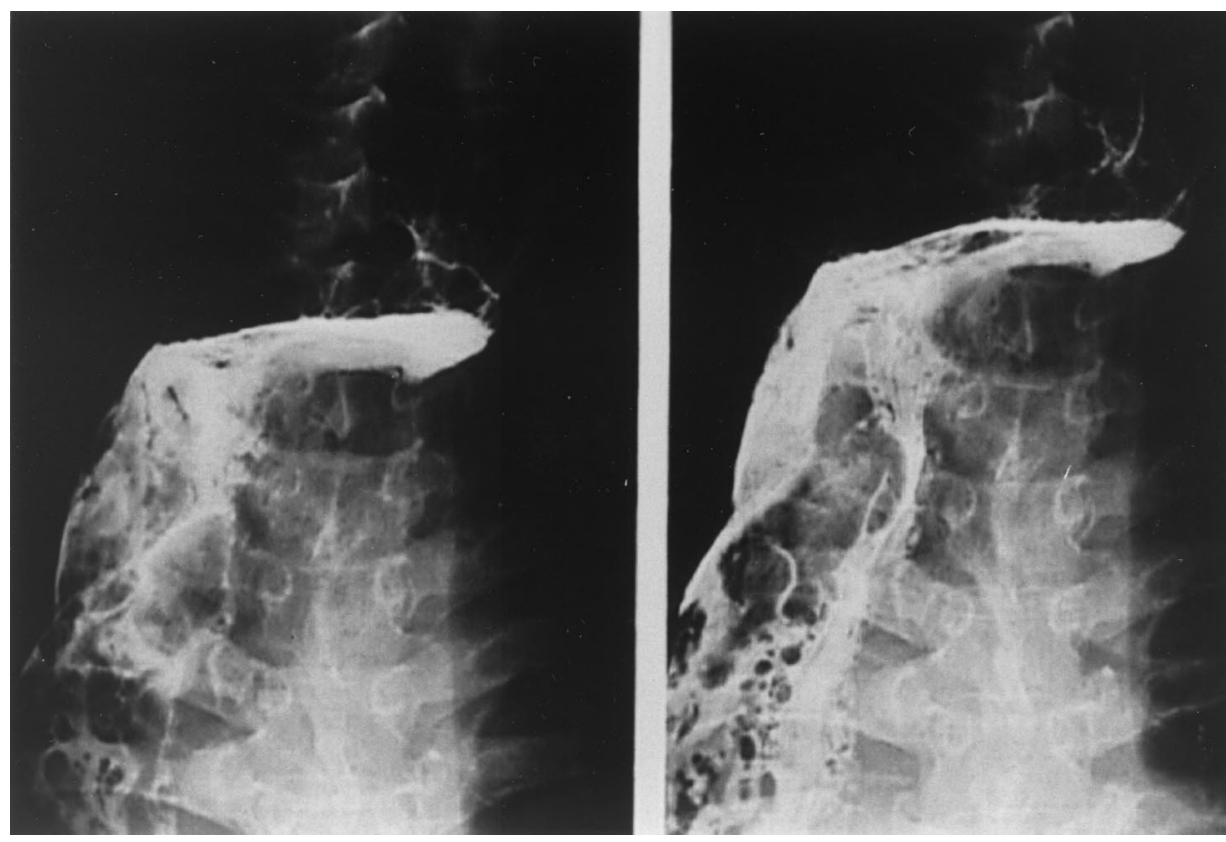

Figure 1. Barium esophagogram showing shifting of gastric substitute in upper thorax caused by external compression.

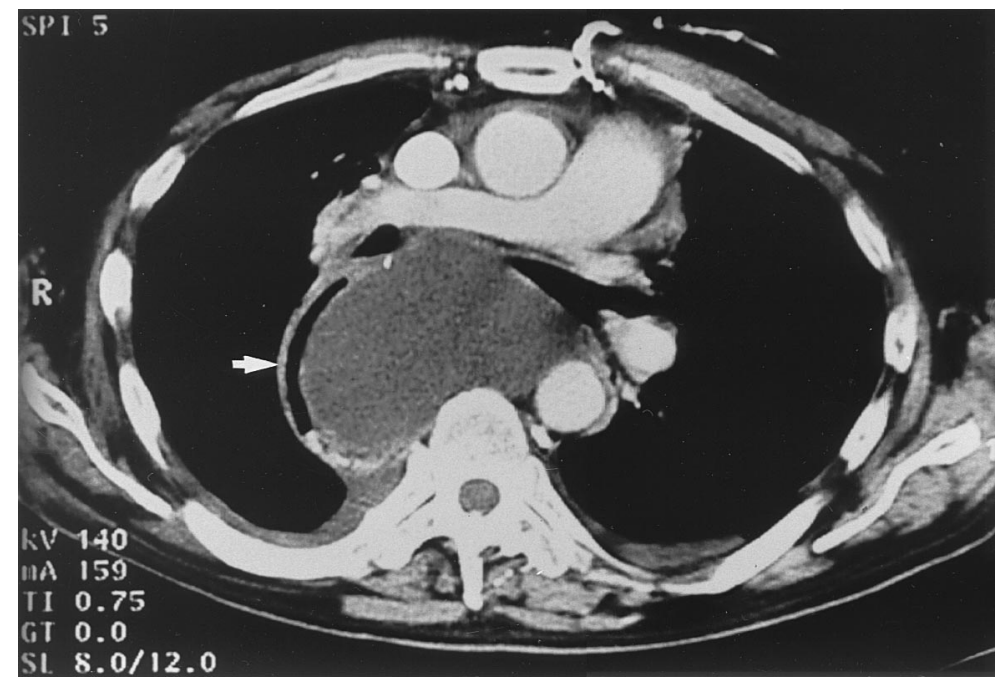

Figure 2. Chest computed tomographic scan showing low-density cystic mass surrounded by thick, contrastenhanced capsule in upper mediastinum. Note that mass compresses stomach (arrow), tracheobronchial tree, and left atrium.

\section{References}

1. Riquet M, Souilamas R, Le Pimpec-Barthes F. Postoperative chylothorax and mediastinal chyloma. Ann Thorac Surg. 2000;70: 2184.

2 Suzuki K, Yoshida J, Nishimura M, Takahashi K, Nagai K. Post- operative mediastinal chyloma. Ann Thorac Surg. 1999;68: 1857-8.

3. Sinclair D, Woods E, Saibil EA, Taylor GA. Chyloma. J Trauma. 1987;27:567-9

4. Milano S, Maroldi R, Bozzola G, Battaglia G, Mombelloni G. Chylothorax after blunt chest trauma: an unusual case with a long latent period. Thorac Cardiovasc Surg. 1994;42:187-90. 